\title{
Application Analysis of the Ecological Value of Agricultural Lands in the Upper Yongding River Basin
}

\author{
Wenbin Zang', Yicheng Fu' ${ }^{1 *}$, Jian Zhang ${ }^{1}$, Wanli Shi', Zhan Qian², \\ Wenxian Guo ${ }^{3}$, Laisheng Liu ${ }^{1}$ \\ ${ }^{1}$ State Key Laboratory of Simulation and Regulation of River Basin Water Cycle, China Institute \\ of Water Resources and Hydropower Research, Beijing, P.R. China \\ ${ }^{2}$ Hunan Province Hydro and Power Design Institute, Changsha Hunan, P.R. China \\ ${ }^{3}$ The Yellow River Institute of Science, North China University of Water Resources and Electric Power, \\ Zhengzhou, Henan, P.R. China
}

Received: 13 December 2017

Accepted: 11 February 2018

\begin{abstract}
The value of agro-ecosystem services is closely related to crop yield. As a production input component in an agro-ecosystem, agro-ecosystem services have practical value. It is generally believed that agroecosystem services are substitutes for purchase investment and can decrease agricultural production costs. Crop yield increases may negatively affect agro-ecosystem protection, and conversely, agroecosystem protection may result in crop yield reductions. Based on the established production model of agro-ecosystems, we determined the reasonable substitutive conditions and production outputs, and we quantitatively studied the ratio of the land area for agricultural production to that for ecosystem services. With the upper Yongding River Basin in China as the study area, we calculated agricultural yield elasticity and concluded that the corresponding crop yield would be reduced by $2.7 \%$ when the land area for ecosystem services in the basin increased by $1.0 \%$. At present, the ecological service value of the Yongding River Basin showed an increasing trend.
\end{abstract}

Keywords: agro-ecosystem, ecological value, land use, production function, negative correlation

\section{Introduction}

As a typical composite ecosystem, a river basin is an ideal management unit to comprehensively solve a series of ecological problems caused by anthropogenic disturbances [1-2]. Ecosystem services (ES) have

*e-mail: swfyc@126.com become a mainstream concept for the expression of values assigned by people to various functions of ecosystems [3]. The watershed agro-ecological value is the currency embodiment of the regional production investment, land cost, and added values of products in the river basin [4]. Agricultural production compensation has seldom been studied from the perspective of public interest. If the land utilization mode benefits from the development of a river basin, local policymakers will excessively exploit the agro-ecological 
value of the river basin, thus leading to an imbalance between the efforts of agro-ecosystem protection and economic development [5]. Agro-ecosystems are the foundation of human activities. In order to improve the renewal capacity of agro-ecosystems, we should build agro-ecological protection mechanisms and carry out legal construction and publicity work to protect agroecosystems. With the help of biodiversity conservation, eco-landscape development, and agro-ecological environment and traditional ecological culture preserve, the agro-ecological protection awareness of farmers was raised. As a result, the coordinated development between the economy and agro-ecological environment protection was achieved [6-9].

According to Simpson, agro-ecosystem services have positive value [10]. To generate the optimal arrangement of agro-ecological value, land area reserved for agricultural production may be reasonably estimated by results of land yields, production value, and agro-ecosystem value. The maintenance cost of the agro-ecological system in a river basin is low. We configurated crop and noncrop areas properly at regional and landscape levels to ensure ecological security and stability, and applied diversified planting and optimized farming practices at the field scale to reconcile agricultural production and nature conservation. Therefore, integrating landscape planning with eco-cycle engineering could achieve the efficient utilization of agricultural resources. However, if ES are considered a substitute for purchase investments, and if excessive attention is paid to ecosystem protection or re-habilitation to attain the highest ecosystem service level, the larger land area will be protected or re-habilitated to ES. Thus, more investments become involved in crop production, and the equilibrium of the agro-ecosystem will be disturbed. Therefore, if ES are considered substitutes for purchase costs, the value of the crop yield in the ecosystem will be negative. The social-ecological system of the region is embedded in a series of nested social-ecological systems in accordance with the multilevel nature of ES stewardship [11-13].

The protection of an agro-ecosystem is affected by crop yield increases. The productivity of farmland will gradually decrease after ES is decreased [14]. Agroecosystem protection depends on the prices of the input and output of agricultural production. ES provides land owners with material inducement and influences the execution force of ecological protection policies. Existing studies of ES were focused on the replacement role of ES for purchase investments. In Nature's Services by Gretchen Daily [15], it was noted that the function of agro-ecosystem services mainly included the generation and renewal of soil fertility, the pollination of crops and natural plants, and agricultural pest control. The agroecosystem in a river basin serves flood control and water purification purposes. Land managers used purchase investments to construct green land and crossroads according to the natural properties of the land. Green infrastructures used in agricultural production have many benefits, including diversified product categories, best management practices (BMPs) standardization, and land intensification [16-17].

\section{Materials and Methods}

\section{Analyzing Substitutive Conditions}

The value of agro-ecosystem services is usually considered as a substitute for purchase investment aside from complementary input. In the production function of the agro-ecosystem, the input of agricultural production is integrated with the yield. Based on the results of Simpson [10], the correlation between the yield, input of land, quantity of supplied ES, and land area is expressed as:

$$
q=f(x, S, A)
$$

...in which $q$ represents the yield, $x$ is the quantity of purchase investment, $S$ represents the quantity of the supplied ES, and $A$ is the land area directly utilized for agricultural production.

The intensified degree of land utilization can be measured by the ratio of the vegetation area to the area of the waterproofing surface. Partial land that is directly used in production activities may be converted into a preserved area to supply ES. Based on the results by Simpson [10], the production capacity of land, $S$, can be expressed simply as:

$$
S=\varphi \cdot(\bar{A}-A)
$$

... in which $\bar{A}$ represents the land area of the land owner, $A$ represents the land area used directly for production, and $\varphi$ is the parameter used for determining the productivity of the preserved land that supplies the ES.

The value of ES decreases with the increase in the land area used for cultivation, A. In Eqs. (1) and (2), $A$ does not necessarily denote a linear correlation between the quantity of any service supplied by the ecosystem and the area of preserved land. For example, it is assumed that the capacity of a natural ecosystem to filtrate nutrient materials is a diminishing exponential function, or in an area with the size of $\bar{A}-A$, species diversity can be described by the power function [18].

Assuming that $r$ represents the price of the input, if the price of yield is normalized as 1 , the profit of the land owners, $\eta$, is determined as:

$$
\eta=f(x, S, A)-r \cdot x
$$

During purchase investment, to maximize the profit, we get:

$$
f_{x} \leq r
$$

To improve the intensity of land utilization, we get: 


$$
f_{A}-\varphi \cdot f_{s} \geq 0
$$

...in which the subscript letter represents partial derivatives, $f x=\partial f / \partial x$. in the case of first-order conditions, Eqs. (4) and (5) are most likely unequal equations. For the land purposed for the development of ecosystem value, the abandonment of the purchase investment is most likely the optimal choice. During agricultural production, maximized intensive land utilization is most likely the optimal choice. In this study, we discussed the unequal forms of Eqs. (4) and (5).

In previous studies, the ecosystem service was assumed to be the substitute for the purchase investment because producers could save on costs by lowering the intensified degree of land utilization and by largely depending on natural investment [19-20]. The concept of substitution is defined as follows: When the purchase price increases, the larger land area is preserved to supply ES, and ES will become the substitute for the purchase investment [21-22]. Therefore, if $\mathrm{d} S / \mathrm{d} r>0, S$ will be the substitute for $x$. The total sum of the area of the preserved land and the area of the land used for direct production is the area of the existing land, $\bar{A}$. The area of the land that supplies the ES can be determined by the area of the preserved land: $\mathrm{d} S / \mathrm{d} r=-\mathrm{d} A / \mathrm{d} r$.

In the case of first-order conditions, Eqs. (4) and (5) are equivalent. If the differential coefficient is calculated concerning $r$, then:

$$
\begin{gathered}
f_{x x} \cdot \frac{\mathrm{d} x}{\mathrm{~d} r}-\left(\varphi \cdot f_{x S}-f_{x A}\right) \frac{\mathrm{d} A}{\mathrm{~d} r}=1 \\
\left(f_{x A}-\varphi \cdot f_{x S}\right) \frac{\mathrm{d} x}{\mathrm{~d} r}+\left(\varphi^{2} \cdot f_{S S}-2 \varphi \cdot f_{s A}+f_{A A}\right) \frac{\mathrm{d} A}{\mathrm{~d} r}=0
\end{gathered}
$$

If $\mathrm{d} x / \mathrm{d} r$ is removed from Eq. (7) according to Eq. (6), then:

$$
\frac{\mathrm{d} A}{\mathrm{~d} r}=\frac{\varphi \cdot f_{x S}-f_{x A}}{f_{x x}\left(\varphi^{2} \cdot f_{S S}-2 \varphi \cdot f_{s A}+f_{A A}\right)-\left(\varphi \cdot f_{x S}-f_{x A}\right)^{2}}
$$

To satisfy the second-order condition of maximal profits, the denominator in Eq. (8) should be positive. The purchase investment is a supplement to the land that is directly used for production. If the numerator of Eq. (8) is negative, the purchase investment partly replaces the ES.

\section{Input and Output Analysis}

The contradiction between economic development and ecological appeal is becoming increasingly serious. Technical efficiency and progress had a positive influence on the growing of agricultural total factor productivity in China, and the major drivers of agricultural growth were still dependent on element input. Therefore, it is necessary to explore whether the ecological value supplied by the land can satisfy the demand for sustainable development in the case of a decreasingly intensified degree. If the intensified degree of land utilization decreases, the purchase investment $x$ and the total yield $q$ will be changed accordingly. Therefore, the total differential of production relation concerning $A$ can be expressed as:

$$
\frac{\mathrm{d} q}{\mathrm{~d} A}=f_{x} \cdot \frac{\mathrm{d} x}{\mathrm{~d} A}-\varphi \cdot f_{S}+f_{A}
$$

If the choice of land intensification is similar to the current status for realizing maximal profits, the condition for Eq. (5) is satisfied. If the total differential of Eq. (4) concerning $A$ is calculated, combined with Eq. (9), we get:

$$
\frac{\mathrm{d} x}{\mathrm{~d} A}=\frac{\varphi \cdot f_{x S}-f_{x A}}{f_{x x}},
$$

The requirement of the second-order condition for maximal profits is $f_{x x}<0$. According to Eqs. (10) and (8), when the ecosystem service is the substitute for the purchase investment, $\mathrm{d} x / \mathrm{d} A>0$.

It is assumed that land is allocated for two uses (ecological protection and production) to acquire maximal profit $\varphi \cdot f_{x s}$. If the ecosystem service is the substitute for the purchase investment, combined with Eqs. (9) and (10), we get:

$$
\frac{\mathrm{d} q}{\mathrm{~d} A}=f_{x} \cdot \frac{\varphi \cdot f_{x S}-f_{x A}}{f_{x x}}>0,
$$

If less land is preserved to supply ES ( $A$ is increased), production activity will be increased. When more land is preserved to supply ES, production activity will be decreased.

For land owners, if more land is preserved to supply ES and less land is used for agricultural production, even though the profit is not reduced, the yield will decrease. This implies a rising market price. If the yield is normalized as one, the corresponding purchase price will be reduced. According to Eq. (8), the simulation impetus of other producers to decrease the intensified degree of land utilization will be reduced.

If the interests of the individual or farmland are dependent on the effect of ES, they will decrease the total production activity. Eq. (11) is a strict unequal equation, implying that the advocator of ecological protection will reasonably analyze the concrete starting point and the intention of producers who want to change their activities.

At present, the advocates of ecological protection have not sufficiently considered the situation that the partial farmland that was previously used to produce crops may be used to supply ES. Therefore, crop yield will inevitably be reduced, and food type (product transition) will be necessarily changed. Therefore, an increase in the ecological protection area in one region will most 
likely increase the risk of regional degradation in another region. The contradiction or negative correlation has been mentioned in relevant agricultural protection plans [19-20]. However, the problems caused by ecological protection that are realized with the method of ES have not been sufficiently addressed [23].

\section{Establishing an Estimation and Calculation Model}

The management efficiency and resource allocation efficiency of the agriculture department should be improved. Therefore, we should improve the scale efficiency of agricultural production by cultivating a new management body of production [24]. The constant profit of a massive production function is expressed as [25]:

$$
q=\sqrt{x \cdot S}-\gamma \cdot x \cdot S / A
$$

...in which the variables are the same as above; $\gamma$ is a positive constant. This is a simple production function with limitation. When the price of the yield is normalized as one, the profit $\eta$ is expressed as:

$$
\eta=\sqrt{x \cdot S}-\gamma \cdot x \cdot S / A-r \cdot x
$$

For $x$, the first-order condition for maximal profit is expressed as:

$$
\left\{\begin{array}{l}
\frac{1}{2} \sqrt{S / x}-\gamma \cdot S / A-r=0 \\
-\frac{\varphi}{2} \sqrt{x / S}+\gamma \cdot x \cdot \frac{\varphi \cdot \bar{A}}{A^{2}}=0
\end{array}\right.
$$

When the first-order Eq. (14) is satisfied, the secondorder condition for maximal management is also satisfied. After the conversion, we get:

$$
x=\frac{S}{4(\gamma \cdot S / A+r)^{2}} \quad A=\frac{\bar{A}}{1+\sqrt{r / \gamma \cdot \varphi}}
$$

The productivity of the land that is directly used for production is improved. However, the ES of the preserved land are determined by the parameter $\varphi$. In other words, if a small quantity of ES is consistently effective, it is not necessary to allocate more land to supply such services.

In the production function, ES and the purchase investment are the substitute items. When the purchase price increases, the area of the land used for production will decrease, suggesting that more land should be preserved. When more land is preserved for maximal profit, the yield will decrease. When Eq. (14) is multiplied by $x$, we get:

$$
\frac{1}{2} \sqrt{x \cdot S}-\gamma \cdot x \cdot S / A-r \cdot x=\eta-\frac{1}{2} \sqrt{x \cdot S}=0
$$

The total differential of Eq. (16) is calculated concerning $\mathrm{A}$. If $\mathrm{A}$ and $\mathrm{x}$ are used to realize maximal profits, the arithmetic resolution can be calculated as:

$$
\frac{\mathrm{d} x / x}{\mathrm{~d} A / A}=\frac{A}{\bar{A}-A}
$$

Therefore, when a majority of the land is used for production, the dependence on the purchase investment is increased. If more land is used in agricultural production activities, greater costs will be paid to compensate for the lost ES. If the initial consideration is the excessive dependence on purchase investments, the margin rate of the technical replacement of the purchase investment by ES will be increased, indicating that the purchase investment will be reduced significantly.

If the land area used for agricultural production is changed, to maximize profits $(\partial q / \partial x=r)$, we get:

$$
\frac{\mathrm{d} q / q}{\mathrm{~d} A / A}=\frac{r \cdot x}{q} \frac{A}{\bar{A}-A}
$$

If agricultural production is dependent on the purchase investment in the current river basin to a greater degree, a significant yield reduction will occur.

\section{Results and Discussion}

The Yongding River $\left(112^{\circ}-117^{\circ} 45^{\prime} \mathrm{E} ; 3^{\circ}-41^{\circ} 20^{\prime} \mathrm{N}\right)$ is one of seven major water systems in the Haihe River Basin. The upper stream of the Yongding consists of the Shanggan River and the Yanghe River, which originate from the southwestern part of Shanxi and the southern part of Inner Mongolia, respectively. Both rivers flow through Guanting Reservoir. After flowing through the reservoir, the Shanggan and Yanghe converge at Qujia Village and form the Yongding. The Yongding enters the sea via Beitang. The Yongding River Basin is located in a semi-arid and semi-humid monsoon climate region, and the climate in the basin is classified as a cold temperate continental climate. Based on administrative divisions, the river basin upstream of the Guanting Reservoir of the Yongding mainly includes the Inner Mongolia Autonomous Region, Shanxi Province, Hebei Province, and Beijing, as shown in Fig. 1. The river basin includes 32 cities, regions, and counties. The upper river basin of the reservoir was considered the study area. The administrative region includes the cities of Datong and Shuozhou in Shanxi Province and Zhangjiakou in Hebei Province. The representative region is in the upper Yongding River Basin. Agricultural production in this region is well developed. This region has an important influence on hydrological conditions, and the major pollutants in the river basin are from the upper stream. The nitrogen fertilizer application is excessive for agricultural production in the Yongding River Basin, leading to the overall loss of $96 \mathrm{~kg} / \mathrm{ha}$ nitrogen [25]. The 


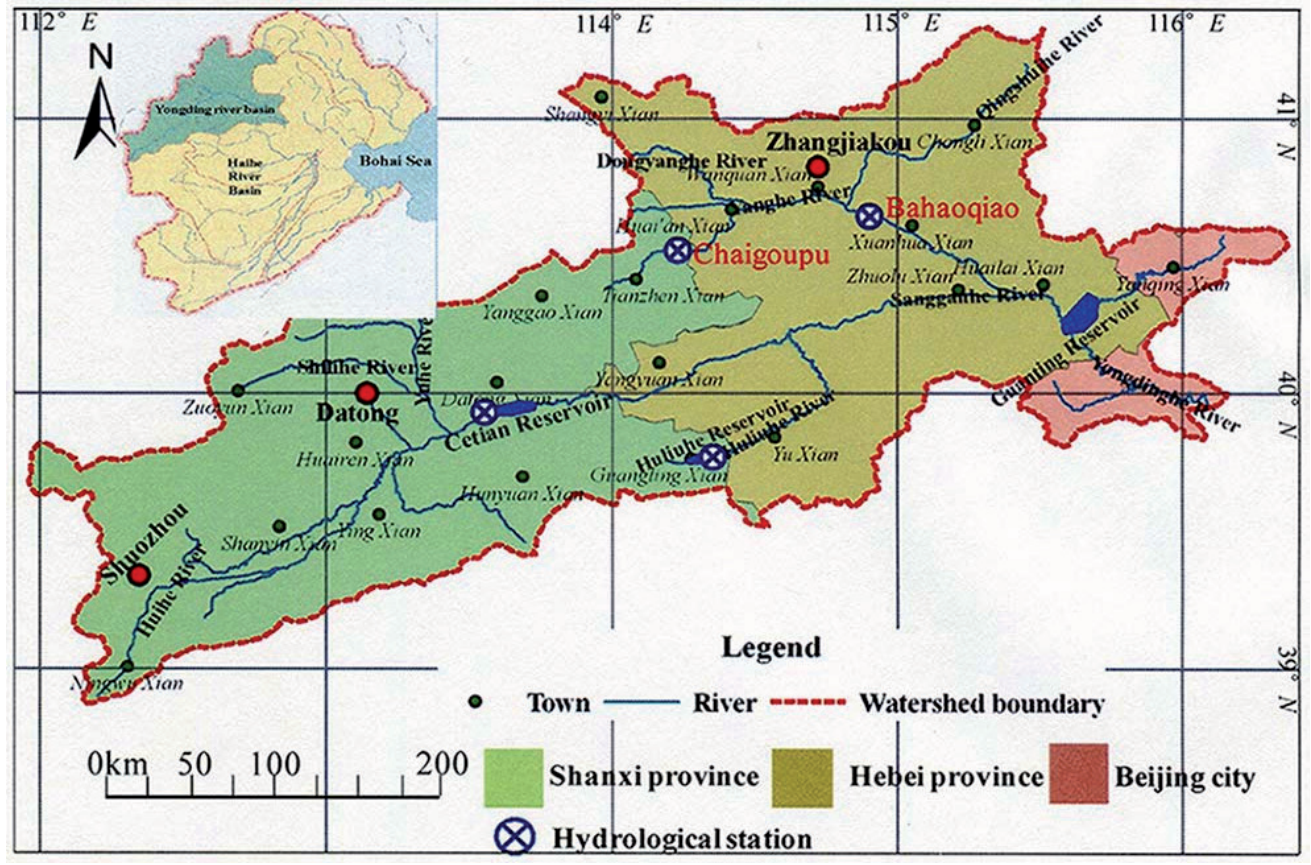

Fig. 1. Yongding River Basin.

phosphorus fertilizer application in the basin is high during agricultural production and the loss per unit area is $9 \mathrm{~kg} / \mathrm{ha}$. To realize the sustainable agricultural production in the watershed, the downstream governments should pay approximately $\$ 21.81 \mathrm{M}$ (¥135 million) to upstream governments for water and soil conservation [26].

\section{Assessing Agricultural Production Value}

The data source of this paper is the remote sensing (RS) image of the TM (thematic mapper) and ETM+ (enhanced thematic mapper plus) in 2007. The land utilization types were classified and extracted based on geometrical modification and image splicing of an RS image using a hierarchical classification method [27].
Field investigations and visual interpretations were performed. The data were supplied by www.geodata.cn, a national science and technology basic conditions platform and an earth system science data-sharing platform; therefore, the data are public. A representative zone was selected for assessing RS interpretation accuracy, and the accuracy was $82.4 \%$. Based on a statistical analysis of the extracted results, the area of cultivated land was approximately 683,469 ha, accounting for $18.4 \%$ of the total river basin; the grassland area comprised 1,115,800 ha, which played a significant role in preventing water erosion, regulating the regional climate, blocking the wind, and fixing sand. The forest area comprised 728,600 ha. The land utilization conditions in the upper Yongding River Basin are shown in Table 1.

Table 1. Land area (ha) in the Yongding River Basin.

\begin{tabular}{|c|c|c|c|c|c|}
\hline \multirow{2}{*}{ Water resource regionalization } & \multicolumn{2}{|c|}{ Administrative regions } & \multirow{2}{*}{$\begin{array}{l}\text { Cultivated } \\
\text { land }\end{array}$} & \multirow{2}{*}{ Grassland } & \multirow{2}{*}{ Forest } \\
\hline & Provinces & Cities & & & \\
\hline \multirow{4}{*}{$\begin{array}{l}\text { The upstream of Cetian Reservoir in the Yongding } \\
\text { River Basin }\end{array}$} & \multirow{3}{*}{ Shanxi } & Datong & 102,709 & 167,678 & 109,491 \\
\hline & & Shuozhou & 206,105 & 336,478 & 219,714 \\
\hline & & Xinzhou & 2706 & 4,418 & 2,885 \\
\hline & \multicolumn{2}{|c|}{ Total } & 311,520 & 508,574 & 332,090 \\
\hline \multirow{3}{*}{$\begin{array}{c}\text { Between Cetian Reservoir and Sanjiadian in the } \\
\text { Yongding River Basin }\end{array}$} & Hebei & Zhangjiakou & 257,068 & 419,677 & 274,043 \\
\hline & Shanxi & Datong & 114,881 & 187,549 & 122,467 \\
\hline & & tal & 371,949 & 607,226 & 396,510 \\
\hline \multicolumn{3}{|c|}{ The Yongding River Basin } & 683,469 & $1,115,800$ & 728,600 \\
\hline
\end{tabular}

Forest types include coniferous, broadleaf, and mixed forest and brushwood; grassland includes grassland meadows, desert meadows, and alpine and shrub grassland 
During the assessment of the value of agricultural products, agricultural products, mature forests, and wetland materials in the upper Yongding River Basin were selected for analysis [28]. Considering the acquisition difficulty of the data for the production value of agricultural products in the river basin, a simple measurement and calculation method was adopted to assess product value according to the analysis results of the measurability of the market value of agricultural products. Based on the established production model of agro-ecosystems, we quantitatively studied the ratio of the land area for agricultural production to that for ecosystem services. We have proposed a calculation system of eco-compensation standard for sustainable agricultural development based on the convertibility between emergy and price [26]. Finally, we used literature citations effectively to support quantification of the relationship between crop yield and ecological value and they concluded a negative correlation between agroecological value and farmland area.

\section{Value of Agricultural Products of Cultivated Land}

Because the non-natural ecosystem of cultivated land is greatly influenced by human activity, the ecological service value of agricultural products per unit area of cultivated land in the river basin can be calculated using the market value. At present, the ecological service value of the cultivated land can be assessed according to the biomass per unit area and the equivalent weight factor. Based on the zoning situation of crops specified in the Annals of China Agriculture in 2007 and the statistical data of key crops in Shanxi and Hebei Provinces, wheat, corn, beans, potatoes (sweet potatoes and potatoes), cotton, peanuts, vegetables, and fruits were used as the study objects, and the distribution areas and relevant variables were elaborated [27]. During the calculation, the yield per unit area was calculated and then corrected based on the statistical data of various zones, the plantation area, total yield, and the mean yields of similar zones in China. Agricultural data includes farmland area, agricultural inputs (fertilizers, pesticides, agricultural machinery, etc.), irrigation data, and crop yield, which were taken from the China Statistical Yearbook and Chinese agricultural statistics data, et al. We got agricultural input data from the "China Statistical Yearbook 2008." Irrigation data were obtained from "China Water Resources Bulletin 2007" and "Yearbook of China Water Resources 2007." Crop yield and farmland area come from "China Rural Statistics Yearbook 2007." The value of the agricultural products of the representative area was calculated to be $¥ 20.02$ billion

\section{Economic Value of Timber Forest}

In 2007 the total forest area was $728.6 \mathrm{~km}^{2}$; the mean price of timber was $¥ 625 / \mathrm{m}^{3}$; the integrated rate of the timber output was $50 \%$; the selected cutting strength was
$36 \%$; and the accumulated volume of the timber per unit area was $149 \mathrm{~m}^{3} / \mathrm{h}$. According to the comprehensive analysis results, the value of the forest products in the river basin was $¥ 1.22$ billion.

\section{Production Value of Wetland Materials}

During wetland utilization, the beach and the wetland can be used to develop fisheries, aquaculture industry, and agricultural plantation. The wetland value is usually assessed according to the direct value. However, the production value is low because the wetland in the river basin is typically the natural reserve. Wetland vegetation is typically natural vegetation, and its value is dominated by its ecological service value. Therefore, its market value is very low, and it is difficult to exploit wetland. The water storage area in the river basin was small, and the density of the aquaculture was low. Therefore, the value of the wetland material products in the river basin was not calculated in this paper.

After a comprehensive analysis, the production value of agricultural land in the upper Yongding River Basin was $¥ 21.24$ billion.

\section{Assessing Agricultural Production Costs}

\section{Total Agricultural Production Costs}

In this paper we calculated the agricultural production costs under environmental protection according to the relationship between the economic value and energy value of the ecosystem. The calculated agricultural production costs correspond to the energy value of the beneficial ES. The energy value of the beneficial environment and agricultural production investment in the Yongding River Basin was determined [29]. Based on a systemic analysis of the investment in materials and labor during agricultural production in the Yongding River Basin combined with the determined different types of energy values, we proposed that the main investment in agricultural production included the investment in the management of water and soil erosion, materials, and the labor force. Based on the input and output in the representative region, we calculated the cost investment of the agro-ecosystem in the Yongding River Basin in 2007.

\section{Material Costs}

During agricultural production, material tools are worn, and the utilization value of the tools is decreased. The various tools for agricultural production are different in service life. Considering the general applications, the energy value of agricultural production material depreciation is determined based on the research results by Coelho.

The total value of water and soil conservation, material investment, and service investment was calculated using the energy price per unit of land area 
Table 2. Investment in agricultural production in the upper Yongding River Basin.

\begin{tabular}{|c|c|c|c|c|c|}
\hline Classification & Details & $\begin{array}{c}\text { Energy value } \\
(\text { Sej/ha })\end{array}$ & $\begin{array}{c}\text { Price of energy } \\
(¥ / \mathrm{ha})\end{array}$ & $\begin{array}{c}\text { Total values } \\
(¥ \mathrm{E}+08)\end{array}$ & $\begin{array}{c}\text { Cost investment } \\
(¥ \mathrm{E}+08)\end{array}$ \\
\hline $\begin{array}{c}\text { Water and soil } \\
\text { conservation }\end{array}$ & Soil erosion & $9.25 \mathrm{E}+14$ & 594.53 & 4.06 & 4.06 \\
\hline \multirow{3}{*}{ Material investment } & Depreciation & $3.05 \mathrm{E}+15$ & $1,960.34$ & 13.4 & 13.4 \\
\cline { 2 - 7 } & Fuel oil & $2.90 \mathrm{E}+13$ & 18.64 & 0.13 & 0.13 \\
\cline { 2 - 7 } & Material & $1.42 \mathrm{E}+16$ & $9,126.83$ & 62.38 & 62.38 \\
\hline \multirow{3}{*}{ Service investment } & Labor & $1.29 \mathrm{E}+16$ & $8,291.28$ & 56.67 & 56.67 \\
\cline { 2 - 7 } & Maintenance and management & $2.51 \mathrm{E}+14$ & 161.33 & 1.1 & 1.1 \\
\cline { 2 - 7 } & Service & $3.30 \mathrm{E}+13$ & 21.21 & 0.14 & 137.88 \\
\hline
\end{tabular}

in the river basin as a reference. The value of agricultural production investment in the Yongding River Basin was calculated indirectly according to the equivalent conversion between the investment and the acquired value. The cost investment for agricultural production in the upper Yongding River Basin was $¥ 1.3788 \mathrm{E}+10$ (Table 2).

\section{Maintenance Cost of Affiliated Facilities}

As an important component of the land, the river basin can directly supply water and indirectly supply fishery products and hydropower. To maintain the integrity of the agro-ecosystem, in addition to routine investment in agricultural production, the maintenance cost of the affiliated facilities would be compensated according to the production situation in the Yongding River Basin. The maintenance cost of the affiliated facilities in the river basin mainly includes fishery production costs and the hydropower generation investment. Based on the production situation of material products, the maintenance cost of affiliated facilities in the upper Yongding River Basin was $¥ 1.155 \mathrm{E}+06$, including $¥ 8.25 \mathrm{E}+05$ of maintenance costs for fishery production in the river basin. The cost is mainly consumed in fry purchase and maintenance in the Cetian and Guanting reservoirs. The maintenance cost of hydropower generation in Guanting Reservoir was $¥ 3.3 \mathrm{E}+05$ [29].

The total production cost in the upper Yongding River Basin was $¥ 137.88 \mathrm{E}+10$. The maintenance cost for the affiliated facilities (hydropower generation and fishery) was $¥ 115.5 \mathrm{E}+05$ (equal to the land remedy cost). After the land cost was deducted, the land production cost was $¥ 137.87 \mathrm{E}+10$.

According to the elasticity of the farmland yield data that were derived from Eq. (18), we get $\theta$,

$$
\theta=\left(\frac{\mathrm{d} q}{q}\right) /\left(\frac{\mathrm{d} A}{A}\right)=\left(\frac{137.87 E+08}{212.40 E+08}\right) /\left(\frac{2977600}{728600}\right)=2.7
$$

...in which $\mathrm{d} q$ is the production cost of farmland after deducting the paid amount, $q$ is the agricultural production value of the farmland, $\mathrm{d} A$ is the total land area after deducting the forest land, and $A$ is the total area of the forest land.

Based on the calculation above, to maximize profit, $1 \%$ of the currently cultivated or used land in Yongding River Basin was converted into preserved land to supply more ES. Accordingly, the crop yield in the river basin was reduced by $2.7 \%$. According to the analysis results based on the ecological value of the vegetation in the Yongding River Basin, the forest land was the main supplier of ES. Therefore, the decrease in crop yield and the increase in the ecological value of forest land are used as the indicators of profit. The research results are representative and reliable.

The model used in this paper was tested with the simple combined data. Because the data were scattered and were difficult to collect, some data used in this paper were the ideal data after secondary processing [30]. Our model suggested that the crop yield decrease was correlated with the increase of ecological effects. Therefore, it is not advisable to neglect this correlation. The upper Yongding RiverBasinisessentiallyaruralareabecauseless than halfof the total area in this river basin is farmland. Like other regions, the reduction of production activity in the river basin has most likely led to the expansion of cultivated land in other regions. However, this negative correlation had not been systematically studied. Therefore, before examining the extensive effect of agricultural ES, it is necessary to be cautious about the benefits gained from the reduction of production activity [31]. The results in this study will provide the technical support for the integrated development of Beijing, Tianjin, and Hebei Province and the renovation of the farmland structure in the river basin. Our results also facilitate the rough measurement and calculation of the reasonable allocation percentage of the land source for maximal ecological and economic benefits in the Yongding River Basin. We used the transfer matrix to analyze the transformation of the land cover types Yongding River Basin. At present, there 
were mainly three kinds of transformations: the natural wetlands changed into cultivated land/unutilized land, the conversion between cultivated land and woodland, and the cultivated land changed into unutilized land [32]. From the different characteristics of landscape unit, we found that the cultivated land area has been decreased. Therefore, the ecological service value of Yongding River Basin showed an increasing trend.

\section{Conclusions}

To generate reasonable farmland protection policies, it is necessary to explore the content of the ecological value of farmland and to quantify the relationship between crop yield reduction and ecological value increases. In the paper, we discussed the negative correlation between the agro-ecological value and the farmland area. If agricultural production in a certain region excessively relies on ES, other regions will be driven to improve the intensified degree of land utilization. This study assumes that the services supplied by natural ecosystems substitute for purchase investments made during agricultural production. This study is also based on the assumption that the producer's objective in policy making is to obtain the maximal amount of profit from the land. Therefore, excessive ES will lead to crop yield decreases. Crop yield decreases in the river basin will lead to a price increase of agricultural products, which may compel producers to increase the investment in agricultural production and expand the cultivated land area. However, to a certain degree, the motivation of agricultural producers to increase ES will be weakened. The upper Yongding River Basin is a mountainous area with low costs for agricultural production. Based on our calculations, the crop yield in this river basin will be reduced by $2.7 \%$ for every $1 \%$ increase in the preserved land area for agricultural services.

Excessive ES will require more preserved land, but it remains unclear whether excessive ES will initiate more ecological protection measures. Therefore, considering the significance of ES, a significant amount of attention should be paid to the relationship between ES and crop yield.

\section{Acknowledgements}

The study was financially supported by the Support Program for University Scientific and Technological Innovation Talents of Henan Province (16HASTIT024), Water Conservation Strategy of Ecological Environment of Typical River and Lake in Hunan Province (Hunan Science and Technology of Water Conservancy [2015]186-11), and the National Key Research and Development Program of China (2016YFC0401408). The authors appreciate the valuable comments and criticisms by anonymous reviewers.

\section{Conflict of Interest}

The authors declare no conflict of interest.

\section{References}

1. LIU Y.H., HUANG S.L., CHEN J.H. Study on the ecosystem-based management for the international river basin. J. Fish China 32, 125, 2008.

2. PING F., TANG X.B., GAO S.T. A comparative study of the atmospheric circulations associated with rainy-season floods between the Yangtze and Huaihe River Basins. Science China-Earth Sciences 57, 1464, 2014.

3. BENNETT E.M., CRAMER W., BEGOSSI A., CUNDILL G., DÍAZ S., EGOH B.N., GEIJZENDORFFER I.R., KRUG C.B., LAVOREL S., LAZOS E., LEBEL L. Linking biodiversity, ecosystem services, and human well-being: three challenges for designing research for sustainability. Current Opinion in Environmental Sustainability 14, 76, 2015.

4. SUN N.L., GONG Q.W., ZHANG J.B. Calculation of the value of agro-ecosystems in Shandong Province. China Popul Resour Environ. 21, 128, 2011.

5. PEARCE D. Paradoxes in biodiversity conservation. World Econ. 6, 57, 2005.

6. RICKETTS, T.H., DAILY, G.C., EHRLICH, P.R., and MICHENER, C.D. Economic value of tropical forest to coffee production. Proc Nalt Acad Sci. 101, 12579, 2004.

7. COSTANZA R., PÉREZ-MAQUEO O., MARTINEZ M.L., SUTTON P., ANDERSON S.J., MULDER K. The value of coastal wetlands for hurricane protection. Ambio 37, 241, 2008.

8. FU Y.C., RUAN B.Q., ZHANG C.L., XU F.R. Yongding River Basin water environmental restoration cost. Journal of Food, Agriculture and Environment 10, 876, 2012.

9. FU Y.C., RUAN B.Q., GAO T. Watershed Agricultural Non-point source pollution management. Polish Journal of Environmental Studies 22, 367, 2013.

10. SIMPSON R.D. Ecosystem services as substitute inputs: basic results and important implications for conservation policy. Ecol Econ. 98, 102, 2014.

11. DI'AZ S., DEMISSEW S., CARABIAS J., JOLY C., LONSDALE M., ASH N., LARIGAUDERIE A., ADHIKARI J.R., ARICO S., BA' LDI A. The IPBES conceptual framework connecting nature and people. Curr Opin Environ Sustain 14, 1, 2015.

12. SCHOLES R.J., REYERS B., BIGGS R., SPIERENBURG M.J., and DURIAPPAH, A. Multi-scale and cross-scale assessments of social - ecological systems and their ecosystem services. Curr Opin Environ Sustain 5, 16, 2013.

13. DURAIAPPAH A.K., ASAH S.T., BRONDIZIO E.S., KOSOY N., O'FARRELL P.J., PRIEUR-RICHARD A.H., SUBRAMANIAN S.M., TAKEUCHI K. Managing the mismatches to provide ecosystem services for human wellbeing: a conceptual framework for understanding the New Commons. Curr Opin Environ Sustain 7, 94, 2014.

14. POWER A.G. Ecosystem services and agriculture: tradeoffs and synergies. Philos Trans R Soc B Biol Sci. 365, 2959, 2010.

15. DAILY, G.C. Nature's services: societal dependence on natural ecosystems. Washington: Island Press.

16. POLLAN, M. The omnivore's dilemma: A natural history of four meals. New York: Penguin. 1997. 
17. HEBERLING M.T., GARCÍA J.H., THURSTON H.W. Does encouraging the use of wetlands in water quality trading programs make economic sense? Ecol Econ. 69, 1988, 2010.

18. MAYER P.M., REYNOLDS S.K., MCCUTCHEN M.D., CANFIELD T.J. Meta-analysis of nitrogen removal in riparian buffers. J Environ Qual. 36, 1172, 2007.

19. WOSSINK A., SWINTON S.M. Jointness in production and farmers' willingness to supply non-marketed ecosystem services. Ecol Econ. 64, 297, 2007.

20. ABLER D. Multifunctionality, agricultural policy, and environmental policy. J Agric Res Econ. 33, 8, 2004.

21. INKOOM J.N., FRANK S., GREVE K., FURST C. A framework to assess landscape structural capacity to provide regulating ecosystem services in West Africa. Journal of environmental management 209, 393, 2018.

22. ZHANG J., FU Y.C., SHI W.L., GUO W.X. A method for estimating watershed restoration feasibility under different treatment levels. Water Science and Technology: Water Supply 17, 1232, 2017.

23. WU J. Slippage effects of the conservation reserve program. Am J Agric Econ. 82, 979, 2000.

24. MARTIN-GUAY M.O., PAQUETTE A., DUPRAS J., and RIVEST, D. The new Green Revolution: Sustainable intensification of agriculture by intercropping. Science of the total environment 615, 767, 2018.
25. GUO W.X., FU Y.C., RUAN B.Q., GE H.F., ZHAO N.N. Agricultural non-point source pollution in the Yongding River Basin. Ecological Indicators 36, 254, 2014.

26. FU Y.C., DU X., RUAN B.Q., LIU L.S., ZHANG J. Agroecological compensation of watershed based on emergy. Water Science and Technology, 76, 2830, 2017.

27. VINCENT J.R., BINKLEY C.S. Efficient multiple-use forestry may require land-use specialization. Land Econ. 69, 370, 1993.

28. XIE G.D., ZHEN L., LU C.X. Applying value transfer method for eco-service valuation in China. J Res Ecol. 1, 51, 2010.

29. FU Y.C., ZHANG J., ZHANG C.L., ZANG W.B., GUO W.X., QIAN Z., LIU L.S., ZHAO J.Y., FENG J. Payments for Ecosystem Services for watershed water resource allocations. Journal of Hydrology, 556, 689, 2018.

30. FU Y.C., GAO T., YAN L.J. Agro-ecological compensation standard based on emergy analysis in Yongding River basin. Transactions of the Chinese Society of Agricultural Engineering 29, 209, 2013.

31. FARLEY J., COSTANZA R. Payments for ecosystem services: from local to global. Ecol Econ. 69, 2060, 2010.

32. ZHAO Y., GONG Z. Analysis of land cover change and its driving force in downstream of Yongding River. Journal of Natural Disasters, 21, 5, 2012. 
